\title{
A formação em pós-graduação na periferia da periferia
}

\section{Graduate Education in the ultra-periphery}

\section{Formación de posgrado en la periferia de la periferia}

Keila Paiva da Silva, mestre em Planejamento do Desenvolvimento pela Universidade Federal do Pará e contadora na Universidade Federal Rural da Amazônia. Endereço: Travessa Mariz Barros, 3066, bloco B, apto. 201 - Bairro do Marco. CEP: 66095-760 - Belém, PA. Telefone: (91) 3231-3572 / 8107-1692. E-mail: keilaufpa@ bol.com.br.

Ana Paula V. Bastos, doutora em Economia pela Universidade de Tsukuba, Japão, e professora dos programas de pós-graduação em Desenvolvimento Sustentável do Trópico Úmido e de Economia da Universidade Federal do Pará. Endereço: Rua Visconde de Ouro Preto, 165, apto 901 - Consolação. CEP: 01303-060 - São Paulo, SP. Telefone: (11) 94866-5827. E-mail: pbastos@ufpa.br.

\section{Resumo}

Este estudo apresenta uma análise a respeito da contribuição do conhecimento adquirido na pós-graduação para o desenvolvimento regional, fundamentando-se em duas correntes: uma que defende a ideia tradicional do investimento em ciência básica como elemento essencial para o desenvolvimento econômico de qualquer região e outra que defende a interdisciplinaridade como resposta à fragmentação causada por uma epistemologia de cunho positivista, que vem ocupando cada vez mais espaço nas universidades brasileiras, com a ampliação crescente de programas de pós-graduação stricto sensu, perante a necessidade que a sociedade do conhecimento, informacional e globalizada impõe à ciência moderna como solução para essa nova forma organizacional. A pesquisa baseou-se na coleta de dados secundários, que foram analisados por meio dos coeficientes de correlação, de especialização e de reestruturação. Os resultados mostraram que a desigualdade 
regional ainda limita o processo de formação e, consequentemente, de inovação do País, sendo que esses são alguns dos fatores que impedem o crescimento econômico equitativo das regiões.

Palavras-chave: Inovação. Conhecimento. Universidade. Interdisciplinaridade. Desenvolvimento Regional.

\section{Abstract}

This study presents an analysis of the contribution of knowledge acquired in graduate schools for regional development. The investigation is grounded in two lines of reasoning: one based on mainstream studies that consider investment in basic science to be an essential element for the economic development of any region and the other which defends interdisciplinarity as a response to the fragmentation caused by a positivist epistemology of nature that has been increasingly occupying space in Brazilian universities with the expansion of graduate study. This fact contradicts the needs of the knowledge society, informational and globalized, which imposes modern science as a solution for this new organizational form. The research was based on the collection of secondary data which were analyzed using coefficients of correlation, specialization and restructuring. Results show that regional inequality limits processes of education and, consequently, of innovation, which are among the factors that prevent the equitable economic growth of regions.

Keywords: Innovation. Knowledge. Universities. Interdisciplinarity. Regional Development.

\section{Resumen}

Este estudio presenta un análisis sobre la contribución de los conocimientos adquiridos en el posgrado para el desarrollo regional, basándose en dos corrientes: una que defiende la idea tradicional de invertir en la ciencia básica como elemento esencial para el desarrollo 
económico de una región y otra que defiende la interdisciplinariedad como respuesta a la fragmentación causada por una epistemología positivista que ocupa cada vez más espacio en las universidades brasileñas, con la expansión creciente de programas de posgrado stricto sensu frente a la necesidad que la sociedad del conocimiento, de la información y globalizada impone a la ciencia moderna como una solución a esta nueva forma de organización. La investigación se basó en la recopilación de datos secundarios que fueron analizados por medio de los coeficientes de correlación, especialización y reestructuración. Los resultados mostraron que la desigualdad regional todavía limita el proceso de formación y, por tanto, de innovación del país. Estos son algunos de los factores que impiden el crecimiento económico equitativo de las regiones.

Palabras clave: Innovación. Conocimiento. Universidad. Interdisciplinariedad. Desarrollo Regional.

\section{Introdução}

A condição de periferia é um constructo teórico discutido por autores como Wallerstein (2004) e Cardoso (1979) e pode condicionar as aspirações de uma região ou país a se desenvolver ou convergir para patamares mais avançados de desenvolvimento. Por um lado, regiões periféricas apresentariam sistematicamente menor propensão a atrair investimentos devido a um menor acúmulo de capacidades instaladas e a uma trajetória de desenvolvimento mais lenta que outras regiões. Por outro lado, diversas abordagens interdisciplinares buscam encontrar as causas da diferença do desenvolvimento e que ligações seriam virtuosas. No campo da economia da inovação, existem vários estudos que comprovam a ligação das ciências básicas com o desenvolvimento das nações, a exemplo de Nelson (1993), Stokes (2005), Mowery e Rosenberg (2005), autores que estudaram os Estados Unidos da América (EUA) como o modelo mais referenciado de país que investiu com intensidade em ciência básica, acreditando na sua contribuição para o desenvolvimento econômico. Deve-se acrescentar que, tal como o Brasil, na transição para o século XIX, os EUA, de colônia, passaram à condição de país independente; no entanto, ambos apresentaram uma trajetória de 
desenvolvimento científico e tecnológico bem diferente. O Brasil, além de menor investimento, apresenta proporcionalmente menor produtividade, na medida em que os retornos são mais modestos que os dos países centrais, condicionando-o à posição de periferia. Mais recentemente, diversos esforços vêm sendo realizados para que se ultrapasse essa condição; no entanto, a desigualdade regional brasileira é marcante e essas diferenças podem comprometer o desempenho nacional.

Nessa ótica de desenvolvimento das nações, a produção de conhecimento é uma das ações mais importantes para que isso ocorra (LÜNDVALL, 1996). Na mesma linha, estudos recentes da inovação apresentam evidência empírica sobre o papel das universidades e da ciência como uma importante fonte de oportunidades tecnológicas para a inovação industrial (KLEVORICK et al. apud ALBUQUERQUE; SILVA; PÓVOA, 2005). As universidades são consideradas peças fundamentais nas regiões onde estão inseridas, capazes de fornecer respostas às necessidades da região, elevando o grau de conhecimento, emprego e renda, ou seja, criando possibilidades para estratégias de desenvolvimento regional (SERRA; ROLIM, 2009).

Em uma estratégia de desenvolvimento periférico, apesar de que temos assistido a um crescente investimento em Ciência e Tecnologia (C\&T) (Capes, 2009), devido a uma trajetória dependente baseada em baixa capacidade educacional e produtiva, regionalmente mantém-se a desigualdade na demanda por mais investimentos. Isto é, regiões com menor concentração de pesquisadores possuem menor capacidade de atração de recursos para desenvolver suas atividades. Deve-se acrescentar que se constatou ainda uma estagnação na criação dos programas de ciência básica, que, como acima indicado, apresentam algum retorno social positivo para o desenvolvimento. Desse modo, discute-se a desigualdade regional como uma problemática de periferia (ou de periferia da periferia, já que o Brasil seria periférico).

Constatando essas desigualdades regionais e se baseando nos estudos de autores citados acima (NELSON, 2006; STOKES, 2005; MOWERY; ROSENBERG, 2005), Monteiro (2010) considera que tais características de investimento constituem um problema e discute a 
condição de periferia da Região Norte do Brasil, demonstrando que ali os cursos de pós-graduação que mais são criados são os interdisciplinares ${ }^{1}$ (eram dois em 1999 e passaram para 29 em 2012), o que, segundo o autor, condicionaria o desenvolvimento da região. Por sua vez, Philippi Júnior e Silva Neto (2011) defendem a interdisciplinaridade como a solução para a crise do conhecimento. Ainda segundo os autores, ao utilizaremse estratégias epistemológicas para a apropriação de saberes, faz-se necessário que elas sejam eficientes para a troca de conhecimento, assim como para a construção do saber entre as diversas disciplinas das ciências. Ou seja, que se tragam para a sala de aula os conhecimentos que a sociedade possui e que esses sejam compartilhados em uma visão de parceria, pois dessa forma é que se promoveria a transferência de dados entre os pesquisadores, bem como a aproximação da universidade com a população, quebrando fronteiras e formando profissionais com um perfil distinto dos existentes, com formação básica sólida e integradora, adequada ao meio onde se localiza, colaborando para o seu desenvolvimento. A crise do conhecimento está aliada a certa crise no desenvolvimento, e a discussão se assemelha àquela sobre a necessidade de desenvolvimento regional endógeno (VAZQUEZBARQUERO, 1998). A definição de uma estratégia de construção de conhecimento bottom-up alicerçada no território apresenta pontos comuns.

Cassiolato (2010) afirma que a capacidade inovativa de um país está no conjunto de organizações e instituições que interagem entre si (no espaço), e que a inovação seja capaz de alterar a trajetória tecnológica, ao mesmo tempo em que contribui para a competitividade da sociedade. Nesse contexto, o conhecimento é considerado um dos ativos intangíveis mais valiosos não só para as empresas como também para determinada região ou país. Nessa linha e tendo em consideração o atual estágio ou ciclo econômico dominado pela técnica e preponderância das tecnologias de informação, a universidade pode desempenhar aqui um papel preponderante.

O objetivo deste artigo é discutir a contribuição da formação acadêmica para a inovação tecnológica e para o desenvolvimento regional. Nesse sentido, foram analisados alguns indicadores de inovação,
Assim denominados pela Capes, dentro da grande área Multidisciplinar, abrangendo diversas áreas, ainda que a maioria tenha foco em ciência sociais. 
relacionando-os com indicadores de desenvolvimento; discutiu-se a formação em ciência básica e a interdisciplinaridade como conhecimento em construção e sua relação no desenvolvimento econômico da região amazônica. A discussão inicia-se com a apresentação das influências teóricas e baseadas nos estudos empíricos nos países que se tornaram líderes na invenção e comercialização de novas tecnologias em razão dos investimentos feitos nas indústrias e universidades, principalmente nos EUA nos anos do pós-guerra. Aborda também a evolução das instituições econômicas; a interdisciplinaridade e a relação entre interdisciplinaridade e desenvolvimento regional, tratando do interesse das universidades em qualificar profissionais que tenham conhecimento geral nas mais variadas ciências e que possam contribuir para o desenvolvimento da região onde estão inseridos. Em seguida, são apresentados os indicadores selecionados, os procedimentos de coleta de dados e as análises descritivas. Por fim, apresentam-se as considerações finais, tendo por base o estudo realizado.

\section{Conhecimento e desenvolvimento na Amazônia}

Mesmo uma região periférica como a Amazônia está inserida em um contexto global que vem sofrendo modificações muito rápidas. Castells (2002) descreve a sociedade contemporânea como uma sociedade globalizada, centrada no uso e na aplicação de informação e conhecimento, cuja base material está sendo alterada aceleradamente por uma revolução tecnológica concentrada na tecnologia da informação e em meio a profundas mudanças nas relações sociais, nos sistemas políticos e nos sistemas de valores. Segundo o autor, os registros históricos parecem indicar que, quanto mais próxima for a relação entre os centros de inovação, produção e utilização das novas tecnologias, mais rápida será a transformação das sociedades e maior será a ação das condições sociais sobre as condições gerais para favorecer futuras inovações (CASTELLS, 2002). Sabendo que, apesar de altamente conectado, o mundo não é plano e existem regiões intrinsecamente mais conectadas (MCCANN, 2008), é importante distinguir a importância das proximidades e do conhecimento aplicado para o desenvolvimento de regiões menos densamente conectadas.

Para melhor discutir a questão do conhecimento finalístico e aplicado, utilizamos o esquema que Stokes (2005) usa para classificar as 
pesquisas em desenvolvimento e que ficou conhecido como Quadrante de Pasteur, em homenagem a Louis Pasteur (1822-1895) (Fig. 1). Esse esquema é dividido em quatro quadrantes, entre eles o Quadrante de Bohr, o Quadrante de Pasteur e o Quadrante de Edison.

\begin{tabular}{c|c}
$\begin{array}{c}\text { Pesquisa básica pura } \\
\text { Quadrante de Bohr }\end{array}$ & $\begin{array}{c}\text { Pesquisa básica inspirada pelo uso } \\
\text { Quadrante de Pasteur }\end{array}$ \\
\hline & $\begin{array}{c}\text { Pesquisa aplicada pura } \\
\text { Quadrante de Edison }\end{array}$
\end{tabular}

Fonte: Stokes (2005), adaptado.

\section{Figura 1. Modelo de quadrantes da pesquisa científica e tecnológica}

O Quadrante de Bohr focaliza a pesquisa básica, representando a procura efetuada pelo dinamarquês Niels Bohr (1885-1962) em sua busca por um novo modelo atômico. O Quadrante de Edison inclui a pesquisa guiada exclusivamente por objetivos aplicados, sem procurar por um entendimento mais geral dos fenômenos de um campo da ciência. 0 Quadrante de Pasteur refere-se à pesquisa básica que busca entender as fronteiras do conhecimento, mas que é também inspirada por considerações de uso. Representa exemplo de combinação de objetivos no direcionamento que Louis Pasteur procurava para o entendimento e o uso para fins práticos. A fase dos primórdios da pesquisa é representada no quadrante inferior à esquerda e inclui a pesquisa que não é inspirada pelo objetivo de entendimento nem pelo de uso. Inclui todas as pesquisas que exploram sistematicamente fenômenos particulares sem ter em vista nem objetivos explanatórios gerais nem qualquer utilização prática à qual se destinem seus resultados (STOKES, 2005).

Homma (2008) defende que na Amazônia há a necessidade de se avançar, simultaneamente, para os três quadrantes (Bohr, Pasteur e Edison), sobretudo se considerarmos a pesquisa sobre sua biodiversidade. Essa necessidade deriva do fato de a região ter menor densidade na rede definida por Castells (2002) e outros, e que se caracteriza como peculiar de regiões periféricas.

No entanto, tal como em North e Thomas (1973), discute-se a necessidade das pesquisas científicas serem complementadas por uma 
matriz institucional responsável pela evolução organizacional e pelo desempenho econômico das sociedades ao longo do tempo. Castells (2002) esclarece que a diversidade de contextos culturais em que a economia informacional emerge e evolui não impede a existência de uma matriz comum de formas de organização nos processos de produção, consumo e distribuição. Sem esses dispositivos organizacionais, a transformação tecnológica, as políticas estatais e as estratégias empresariais não estariam em condições de se articular em um novo sistema econômico. Reforçam North e Thomas (1973) que a chave do funcionamento da sociedade está na evolução das instituições, que são um conjunto de regras, formais ou informais, criadas pelos indivíduos para regular a interação entre eles em uma sociedade. Para tais autores, a causa do subdesenvolvimento está justamente no conjunto de instituições, ou seja, de regras do jogo, de normas e valores que orientam a conduta do dia a dia, de orientações que reduzem a incerteza dos indivíduos, que dissociam o trabalho do conhecimento, que dificultam o acesso à terra e que bloqueiam a inovação (ARBIX; ZILBOVICIUS, ABRAMOVAY, 2001). Isso não significa que a estrutura institucional não se modifique nem que ela se torne eficiente; ao contrário, os diferentes padrões de desenvolvimento dos países encontram explicações nos processos de evolução de suas instituições, nos arranjos institucionais que conduzem a desempenhos favoráveis, enquanto outros não (TOYOSHIMA, 1999).

Desse modo, analisando o processo histórico da região amazônica, Costa (2012) aponta que, apesar do estabelecimento das estruturas capitalistas na região nos moldes estudados por outros autores, existem remanescentes de relações mercantis e de poder das elites locais e de uma relação com o bioma que caracterizam particularidades de difícil comparação. É possível e necessário tornar o estado, na Amazônia, permeável à pluralidade de forças que expressam a diversidade social e cultural da região, dotando-o de mecanismos que o façam eficiente como indutor de desenvolvimento pela correção das desigualdades econômicosociais. Esse papel indutor de mudança pode estar dentro da universidade e na sua missão de ensino, pesquisa e extensão.

Dados demonstram que atores privados, com o suporte de instituições do estado por meio de crédito e incentivos diversos, têm 
historicamente aportado à região matrizes tecnológicas inadequadas. O sistema capitalista e seus agentes forjaram as relações de produção, principalmente no que se refere à agropecuária, com as de outros ecossistemas. Tais matrizes desenvolveram-se pelo esforço da ciência em criar sistemas botânicos homogêneos para maximizar a produção de biomassa por uma lógica de industrialização da agricultura fortemente assentada em bases mecânico-químicas (GOODMAN, 1989; ROMEIRO, 1998). As técnicas daí derivadas, por serem aparatos de padronização, negam o capital natural contido na diversidade biológica. Por seu turno, as mesmas características ecológicas da região, que explicam sua gigantesca biodiversidade, negam essas matrizes, reduzindo dramaticamente os ciclos de vida e a economicidade de suas técnicas.

Um macro desafio será, pois, o de alterar as pautas das instituições de Ciência \& Tecnologia na região, para que, atuando orientadas pelo princípio da diversidade, em substituição ao da padronização e da homogeneidade, possam produzir técnicas ajustadas às necessidades regionais. Para Madeira (2000), a visão do conhecimento e de sua construção histórica é colocada no centro da estruturação do processo de pesquisa e de pós-graduação interdisciplinares. Somente nesse nível seria possivel superar a atomização do saber em parcelas de disciplinas "pagas a crédito", trocando-a por uma visão interdisciplinar de integração e síntese desenvolvida pelo conjunto de grupos de pesquisa ou núcleos de estudos, pesquisa e extensão, nas suas linhas em que se agrupam os projetos e nas especificidades de suas áreas. Deve-se acrescentar que talvez não exista a capacidade de organização institucional por imaturidade do sistema de inovação (ALBUQUERQUE, 2005) ou dificuldades de absorção de conhecimento novo por parte da população (COHEN e LEVINTHAL, 1989) característico de regiões menos desenvolvidas (SCHILLER; MILDAHN ; REVILLA DIEZ, 2009).

Nesse sentido, e considerando a desigualdade com outras regiões do País, é inequívoco que, no que se refere ao desenvolvimento regional, o papel das universidades - instituições que sempre deram expressiva contribuição para o desenvolvimento das nações, por meio do ensino, da pesquisa e da extensão - intensificou-se após o processo de globalização, que disseminou uma nova forma de concorrência das 
regiões e o estabelecimento de institucionalidades que conformam sistemas regionais de inovação (SERRA; ROLIM, 2009).

\section{Conhecimento disciplinar versus interdisciplinar}

No mundo globalizado, as universidades passaram a ter um novo papel: o de elevar o nível da capacidade de absorção de conhecimento por parte da sociedade em seu entorno e contribuir com a produção de conhecimento (pesquisas), de forma direta ou indireta, por intermédio da interação com outras instituições, elevando o nível de desenvolvimento de determinada região. Observou-se que as universidades responsáveis pela maior parte das atividades de inovação mantiveram seu foco por muitos anos nos cursos finalísticos ou especialistas (engenharias, biologias, químicas etc.), a chamada ciência básica, vital para o desenvolvimento tecnológico (NELSON, 2006). No entanto, no final do século XX, o paradigma "unidisciplinar" de produção do conhecimento foi considerado insuficiente para responder aos complexos problemas que foram aparecendo, ou seja, havia uma limitação do conhecimento científico disciplinar moderno, a sociedade necessitava de outras formas de abordagem que dessem conta de realidades mais e mais complexas (PHILIPPI JÚNIOR; SILVA NETO, 2011). Teorias de aprendizagem corroboram essa ideia, afirmando que a interdisciplinaridade, por ser mais relacionada ao contexto, é mais fácil de reter e permite o estabelecimento de nexos científicos mais complexos (LATUCCA; VOIGHT; FATH, 2004). Elas também se adequariam ao que Costa (2012) defende: a necessidade de se perceber a complexidade do bioma amazônico para a criação de outros modelos de desenvolvimento regional.

Na seção seguinte, faremos uma tímida tentativa de analisar a questão por meio de evidências empíricas, tendo como ponto de partida os conceitos de regiões distintas, com institucionalidades também distintas. 


\section{Materiais e métodos}

\section{Análise empírica}

Baseado na fundamentação teórica discutida nas subseções anteriores sobre as contribuições das ciências básicas e a interdisciplinaridade para o desenvolvimento dos países/regiões, o estudo procurou identificar variáveis que pudessem medir a contribuição do conhecimento adquirido na pós-graduação, principalmente no doutorado, para o desenvolvimento regional na Amazônia, discussão que obrigatoriamente passa pela comparação com a região que concentra a maior parte dos investimentos e da produção científica brasileira: o Sudeste. A análise dos dados tentou ainda perceber a contribuição do conhecimento na pós-graduação, diferenciando-a entre os programas ditos de ciência básica e os programas interdisciplinares para o crescimento econômico e o desenvolvimento regional.

Para demonstrar o crescimento dos cursos de pós-graduação na área interdisciplinar no Brasil e fazer uma relação com o desenvolvimento regional, funda-se o estudo em uma análise comparativa entre a evolução da pós-graduação das áreas da ciência básica e a área interdisciplinar, no período compreendido entre 1999 e 2012. Ressalta-se que os cursos analisados considerados programas da ciência básica foram os de Engenharia, Ciências Biológicas e Ciências Exatas.

A análise foi feita por meio do coeficiente de correlação (linear) de Pearson, pois ele é apropriado para descrever a correlação linear de duas variáveis quantitativas (BARBETTA, 2005), ou seja, para qualquer conjunto de dados, o valor de coeficiente de correlação de Pearson, $r$, estará no intervalo de -1 a 1. Será positivo quando os dados apresentarem correlação linear positiva; será negativo quando os dados apresentarem correlação linear negativa. A correlação é elevada se o coeficiente se situa entre $|1,00|$ e |0,65|; moderada, se entre |0,64| e |0,30|; e fraca, se entre $|0,29|$ e 0,00, independentemente do sinal (BARBETTA, 2005).

Além disso, tal como Monteiro (2010), fizemos uso de dois coeficientes usados comumente em ciência regional para analisar não 
só a especialização das regiões em relação aos cursos ofertados, como também a sua evolução mais recente.

Os índices de especialização foram recalculados por meio de medidas regionais com o objetivo de investigar o grau de especialização da formação em pós-graduação nas cinco regiões do Brasil, entre dois períodos. As medidas utilizadas foram os coeficientes de especialização e de reestruturação.

O coeficiente de especialização compara a estrutura da formação de uma região (j) com a estrutura nacional. O valor do coeficiente será igual a zero quando a região tiver uma composição de cursos idêntica à nacional. Se o valor do coeficiente for igual a 1, a região j está com elevado grau de especialização em atividades ligadas a determinada área de conhecimento ou está com uma estrutura de formação totalmente diversa da estrutura nacional (HADDAD, 1989), denotando uma condição mais periférica.

$$
C E j=\frac{\sum_{j}(|i \in j-i e .|)}{2}=\text { coeficiente de especialização da regiãoj }
$$

Outro coeficiente analisado foi o de reestruturação, que relaciona a estrutura da formação de uma região (j) com a estrutura nacional, entre dois períodos, a fim de avaliar o grau de mudança na especialização dessa região. Quando o coeficiente for igual a zero, não terá havido modificações na composição de formação da região. Se, por outro lado, o coeficiente for igual a 1, terá ocorrido uma reestruturação profunda na composição de formação da região (HADDAD, 1989).

$$
C T j=\frac{\sum{ }_{j}\left(\left|i_{t o}-i_{t 1}\right|\right)}{2}=\text { coeficiente de reestruturação da região }
$$

A discussão dessas medidas auxiliou na análise dos dados empíricos, e sua análise será realizada após a descrição da coleta de dados. 
Coleta de dados

A pesquisa baseou-se na coleta de dados secundários, os dados quantitativos foram coletados dos sites oficiais da Coordenação de Aperfeiçoamento de Pessoal de Nivel Superior (Capes), do Instituto Nacional de Estudos e Pesquisas Educacionais Anísio Teixeira (Inep), do Instituto Nacional da Propriedade Industrial (Inpi), da Federação de Indústrias do Rio de Janeiro (Firjan) e do Instituto Brasileiro de Geografia e Estatística (IBGE), conforme Quadro 1, em que estão descritas as variáveis, os indicadores, a fonte e o período.

\section{Quadro 1. Resumo das variáveis}

\begin{tabular}{l|l|c|c}
\hline \multicolumn{1}{c|}{ Variáveis } & \multicolumn{1}{c|}{ Descrição das Variáveis } & Fonte & Período \\
\hline $\begin{array}{l}\text { Variação dos } \\
\text { programas } \\
\text { interdisciplinares }\end{array}$ & $\begin{array}{l}\text { Mede a evolução dos } \\
\text { programas de pós- } \\
\text { graduação interdisciplinar }\end{array}$ & Capes & 1999 a 2012 \\
\hline $\begin{array}{l}\text { Variação dos } \\
\text { programas da ciência } \\
\text { básica }\end{array}$ & $\begin{array}{l}\text { Mede a evolução dos } \\
\text { programas de ciência } \\
\text { básica }\end{array}$ & Capes & 1999 a 2012 \\
\hline $\begin{array}{l}\text { Proporção do } \\
\text { número de Doutores }\end{array}$ & $\begin{array}{l}\text { Mede o grau máximo de } \\
\text { formação }\end{array}$ & Capes & 1999 a 2012 \\
\hline IDFM & $\begin{array}{l}\text { Mede o resultado do } \\
\text { investimento em P\&D }\end{array}$ & Inpi & 1999 a 2012 \\
\hline $\begin{array}{l}\text { Mede o nível de } \\
\text { desenvolvimento humano } \\
\text { dos municípios/estados } \\
\text { utilizando como critérios } \\
\text { indicadores de emprego e } \\
\text { renda, educação e saúde }\end{array}$ & Firjan & 1999 a 2010 \\
\hline PIB per capita & $\begin{array}{l}\text { Mede a riqueza média } \\
\text { gerada por pessoa, } \\
\text { resultado da divisão do PIB } \\
\text { pelo número de habitantes }\end{array}$ & IBGE & 1999 a 2010 \\
\hline
\end{tabular}

As duas primeiras variáveis, variação de programas de ciência básica e interdisciplinares, nos permitiu analisar o crescimento da pósgraduação no Brasil e nas regiões.

Outra variável analisada foi o crescimento no número de doutores, variável escolhida não só pela importância do elevado nível de qualificação educacional possível de um indivíduo, como também porque 
eles compõem a parcela dos recursos humanos treinada especificamente para realizar pesquisa e desenvolvimento (CGEE, 2010).

A literatura afirma que os doutores são os responsáveis por desempenhar um papel estratégico nos processos de produção e transmissão de conhecimento e tecnologias (NELSON, 2006; MOWERY; ROSENBERG, 2005; SUZIGAN; ALBUQUERQUE, 2005).

Sabemos, porém, da literatura, que, para avaliar o grau de desenvolvimento de um país, não basta contabilizar o número de doutores. Para isso ocorrer, teriam que basear suas pesquisas no desenvolvimento e na elaboração de novos produtos, ou seja, na inovação, principalmente se eles estiverem ligados à produção industrial (NELSON, 2006). O treinamento de cientistas e engenheiros pelas universidades públicas para empregos em pesquisa industrial uniu as universidades à indústria nos EUA, no pós-guerra (MOWERY e ROSENBERG, 2005). As grandes empresas, juntamente com o governo, investiram em inovação e fortaleceram a política de licenciamento dos direitos de propriedade intelectual, sobretudo as patentes. No Brasil, Cassiolato (2010) defende que existe uma forte ligação entre o número de depósitos de patentes com a variação do PIB (que mede a riqueza monetária da nação) e o nível de investimento em P\&D. De acordo com dados do Ministério de Ciência e Tecnologia (MCT) de 2009, o Brasil investiu 1,42\% do seu PIB em ciência e tecnologia, o que é considerado uma taxa baixa quando comparada à de outros países de industrialização tardia (INPI, 2011). Segundo a SBPC (2011), o Brasil subiu da $27^{a}$ posição no ranking de países que mais registram patentes para a $24^{a}$ posição, entre 2005 e 2009. Em 2009, o registro chegou a 480, superando Irlanda, África do Sul e Nova Zelândia.

O Índice Firjan de Desenvolvimento Municipal (IFDM) é um estudo anual do Sistema Firjan, que acompanha o desenvolvimento de todos os mais de 5 mil municípios brasileiros em três áreas: Emprego \& Renda, Educação e Saúde. Ele é feito exclusivamente com base em estatísticas públicas oficiais disponibilizadas pelos ministérios do Trabalho, da Educação e da Saúde. De leitura simples, o índice varia de 0 a 1. Quanto mais próximo de 1, maior o desenvolvimento da localidade. Além disso, sua metodologia possibilita determinar, com precisão, se a 
melhora relativa ocorrida em determinado município decorre da adoção de políticas específicas ou se o resultado obtido é apenas reflexo da queda dos demais municípios (FIRJAN, 2012).

O PIB mede a riqueza total do país ou da região; e o PIB per capita, sua distribuição média pelo total da população, sendo um importante indicador na literatura de crescimento e desenvolvimento econômico, mesmo quando declarado como limitado e outros indicadores são apontados.

Na subseção seguinte analisaremos os resultados para esse conjunto de dados e variáveis.

Análise descritiva dos dados

Os dados serão analisados para as cinco regiões brasileiras. A série histórica inicial é de 1999 a 2012; no entanto, nem sempre foi possível obter a série completa para todas as variáveis, pois foram usados somente bancos de dados públicos.

A análise se inicia constatando que, enquanto no Brasil como um todo há um aumento de 26 para 236 cursos interdisciplinares, um acréscimo de mais de $800 \%$ em termos absolutos, os cursos aqui considerados de ciência básica tiveram um crescimento mais moderado $(226 \%)$, apesar do fato de que, em valores absolutos, houve um acréscimo de 430 (de 190 para 620) cursos. Esses números, facilmente obtidos no site da Capes e em seus relatórios, mostram uma leve mudança de padrão de formação científica em âmbito nacional. Examinou-se também a evolução dos programas de pós-graduação na Amazônia em relação ao restante do País. Os dados são referentes à Amazônia Legal (Acre, Amapá, Amazonas, Pará, Rondônia, Roraima, Tocantins, Maranhão e Mato Grosso), somados os percentuais de cada programa (Ciência Básica e Interdisciplinar) por estado e por ano, pelo fato de que a maioria desses estados, em 1999, não possuía programa de pós-graduação ou só havia os programas referentes aos cursos da ciência básica - apenas o estado do Pará possuía dois cursos na área interdisciplinar. Verificou- 
se que o crescimento dos programas segue a média nacional, um crescimento relevante nos programas interdisciplinares de dois (1999) para 40 (2012) cursos; em termos percentuais, mais de 1000\% em relação à média nacional, enquanto os programas de ciência básica auferiram um crescimento de $284 \%$ em relação à média nacional, de dez (1999) para 61 (2012), em valores absolutos. Constatou-se que, apesar de ter havido um relevante crescimento nos programas interdisciplinares, principalmente em valores relativos, superando os valores dos programas de ciência básica, em valores absolutos, a diferença nacional é de 384 cursos a mais para os programas da ciência básica, enquanto que, na Amazônia, essa diferença é de 21 cursos a mais. No entanto, os cursos interdisciplinares ganharam espaço, principalmente na Amazônia, mas tais dados ainda não indicam que existe uma diferença na relação entre ciência básica e interdisciplinar na formação da pós-graduação e o desenvolvimento da região amazônica, pois, em termos absolutos, tanto para o Brasil quanto para a Amazônia, o balanço é positivo para a ciência básica.

\section{Quadro 2. Cursos de pós-graduação no Brasil (Ciência Básica/ Interdisciplinar)}

\begin{tabular}{l|c|c|c|c}
\hline \multirow{2}{*}{ UF } & \multicolumn{2}{|c|}{1999} & \multicolumn{2}{c}{2012} \\
\cline { 2 - 5 } & C. Básica & Interdisciplinar & C. Básica & Interdisciplinar \\
\hline Norte & $\mathbf{8}$ & $\mathbf{2}$ & $\mathbf{4 7}$ & $\mathbf{2 9}$ \\
\hline Rondônia & & & 1 & 3 \\
\hline Acre & & & 1 & 2 \\
\hline Amazonas & 3 & & 17 & 6 \\
\hline Roraima & & & 2 & 3 \\
\hline Para & 5 & 2 & 23 & 9 \\
\hline Amapá & & & 1 & 2 \\
\hline Tocantins & & & 2 & 4 \\
\hline Nordeste & $\mathbf{4 7}$ & $\mathbf{5}$ & $\mathbf{1 5 4}$ & $\mathbf{5 5}$ \\
\hline Maranhão & 2 & & 7 & 4 \\
\hline Piauí & 1 & & 6 & 4 \\
\hline Ceará & 4 & 1 & 20 & 10 \\
\hline Rio Grande do & 8 & & 18 & 5 \\
\hline Norte & 11 & 1 & 24 & 6 \\
\hline Paraíba & 15 & 1 & 33 & 7 \\
\hline Pernambuco & 1 & 1 & 9 & 4 \\
\hline Alagoas & & & & \\
\hline
\end{tabular}




\begin{tabular}{l|c|c|c|c}
\hline \multirow{2}{*}{ UF } & \multicolumn{2}{|c|}{1999} & \multicolumn{2}{c}{2012} \\
\cline { 2 - 5 } & C. Básica & Interdisciplinar & C. Básica & Interdisciplinar \\
\hline Sergipe & & 1 & 13 & 2 \\
\hline Bahia & 5 & & 24 & 13 \\
\hline Sudeste & 82 & 6 & 244 & 82 \\
\hline Minas Gerais & 30 & 1 & 91 & 23 \\
\hline Espírito Santo & 4 & & 14 & 5 \\
\hline Rio de Janeiro & 37 & 5 & 92 & 35 \\
\hline São Paulo & 11 & & 47 & 19 \\
\hline Sul & $\mathbf{3 7}$ & $\mathbf{1 1}$ & $\mathbf{1 1 6}$ & $\mathbf{3 6}$ \\
\hline Paraná & 9 & 3 & 37 & 11 \\
\hline Santa Catarina & 9 & 4 & 22 & 9 \\
\hline Rio Grande do Sul & 19 & 4 & 57 & 16 \\
\hline Centro-Oeste & $\mathbf{1 6}$ & $\mathbf{2}$ & $\mathbf{5 9}$ & $\mathbf{3 4}$ \\
\hline Mato Grosso do & 1 & & 12 & 6 \\
\hline Sul & & & 6 & 7 \\
\hline Mato Grosso & & & 15 & 8 \\
\hline Goiás & 4 & 26 & 620 & 236 \\
\hline Distrito Federal & 11 & & & 13 \\
\hline Brasil & 190 & 26 & & \\
\hline
\end{tabular}

Fonte: Elaboração própria, baseado em Geocapes, 2014.

Não é clara a relação de causalidade, mas os dados demonstram que a Região Sudeste é a que apresenta sempre os melhores indicadores de desenvolvimento e nela está concentrada também a maioria dos programas de pós-graduação do País, bem como o maior número de doutores, 36.748 (2012), como veremos no próximo gráfico.

Para mostrar a evolução do número de doutores por grande área entre 1999 e 2012, foram elaborados o Gráfico 1 - Evolução de doutores no Brasil por região e o Gráfico 2 - Proporção de doutores no Brasil por região. Os dados revelam que as regiões Norte, Nordeste, Sul e Centro-Oeste foram as que mais cresceram se comparadas com a Região Sudeste; embora esta apresente o maior número de docentes com doutorado, houve queda na velocidade de seu crescimento. A Região Nordeste foi a que apresentou maior variação $(7 \%)$, seguida do CentroOeste e do Norte (3\%), do Sul (2\%) e do declínio do Sudeste (-15\%). Essa variação deve ser lida com cuidado, uma vez que, no início do período 
analisado, na maioria dos estados da Região Norte, como Tocantins, Roraima, Acre, Rondônia e Amapá, não existiam programas de pósgraduação, pois não havia docentes suficientes para a implantação deles, situação que vem sendo melhorada. Então, como partimos de um nivel muito baixo nesses estados, naturalmente a variação é maior; ademais, com a implementação de programas de pós-graduação, aumentam as possibilidades de se formarem doutores na região e, desse modo, seu número naturalmente aumenta. No entanto, devemos perceber de que na Região Sudeste o número de doutores é mais de dez vezes maior que na Região Norte.

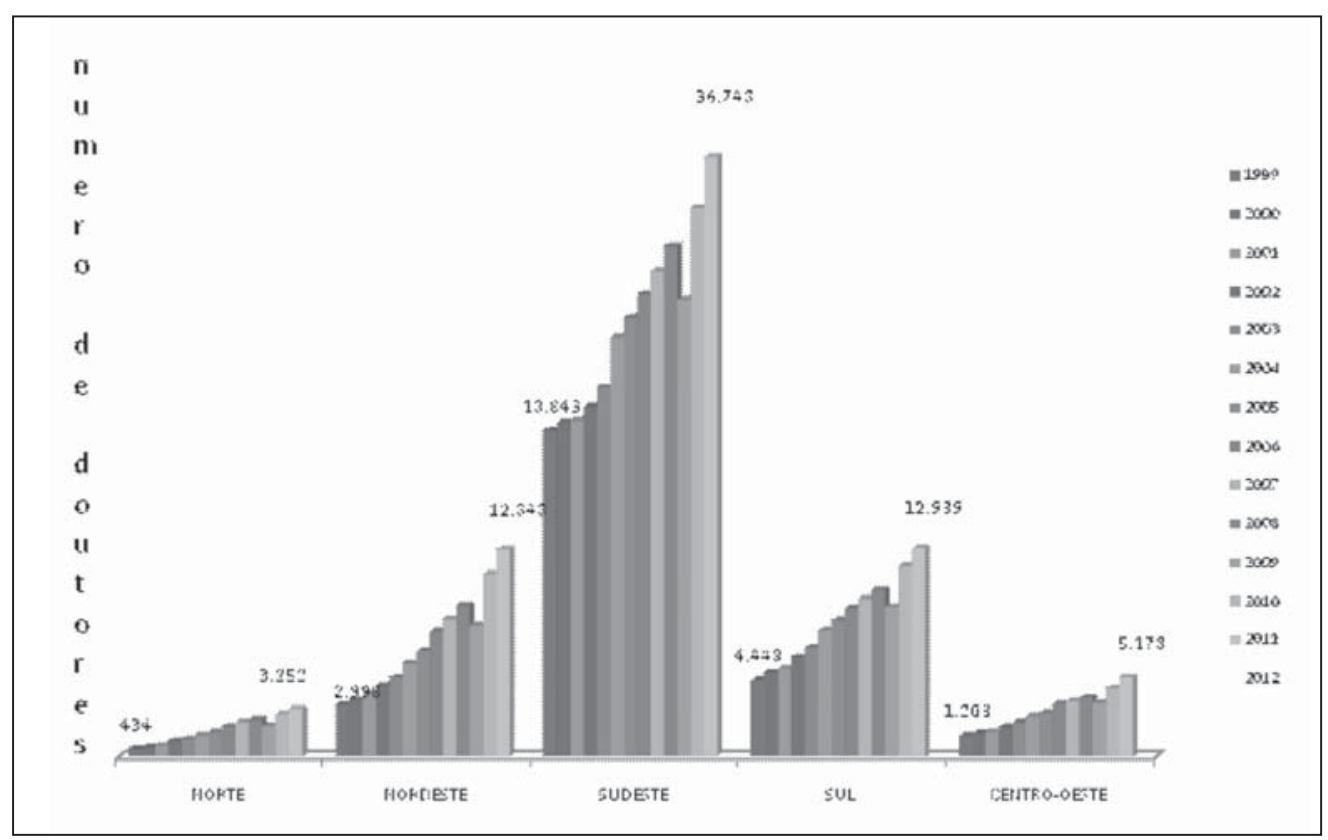

Fonte: Elaboração própria, baseado em Geocapes, 2014.

Gráfico 1. Evolução do número de doutores (docentes) no Brasil por região, período de 1999 a 2012 


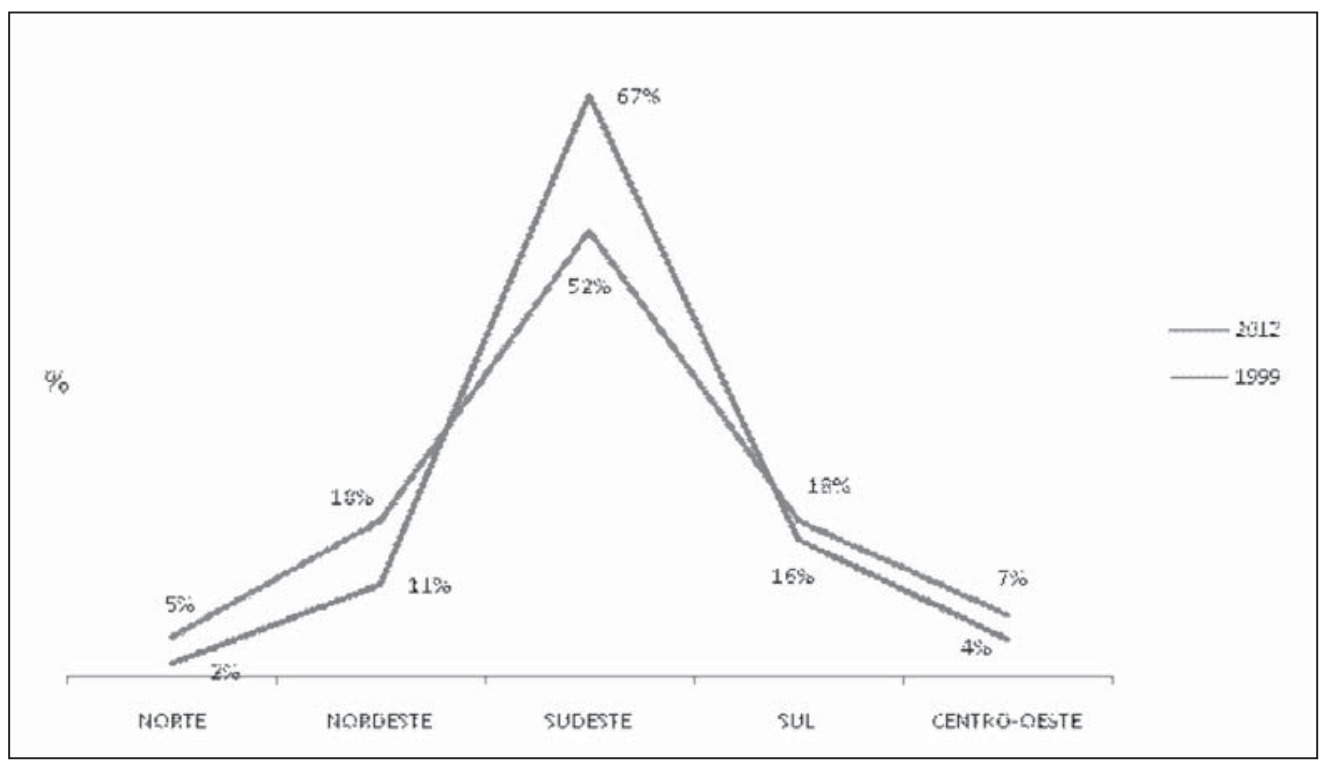

Fonte: Elaboração própria, baseado em Geocapes, 2014.

Gráfico 2. Proporção de doutores (docentes) por região em relação ao total no Brasil nos anos de 1999 e 2012

Observa-se, no Gráfico 2, um achatamento da curva de 1999 para 2012, indicando uma variação positiva no sentido da diminuição da desigualdade regional. O Nordeste apresentou melhor recuperação, mas, com exceção do Sudeste, todas as outras regiões melhoraram a proporção de doutores em relação ao Brasil.

Relativamente ao número de pedidos de patentes, verificou-se que, em todas as regiões, cresceu o número de patentes; no entanto, o Sudeste continua crescendo mais, ainda que proporcionalmente perca seu peso nacionalmente. Apesar das tentativas de catch-up, não se pode falar em convergência, porque o Sudeste apresenta um incremento absoluto maior do que o de outras regiões juntas - Norte, Nordeste e Centro-Oeste. Embora os pedidos de patentes não obrigatoriamente sejam realizados por doutores, uma vez que analisamos aqui o papel da universidade no desenvolvimento, o Gráfico 3 apresenta o comparativo entre a relação do número de doutores e os pedidos de patentes por estado, referente ao ano de 2012. Para cada patente depositada, existem "x" número de doutores que não necessariamente apresentaram pedidos de patente e podem estar desempenhando outras funções não ligadas à inovação. 


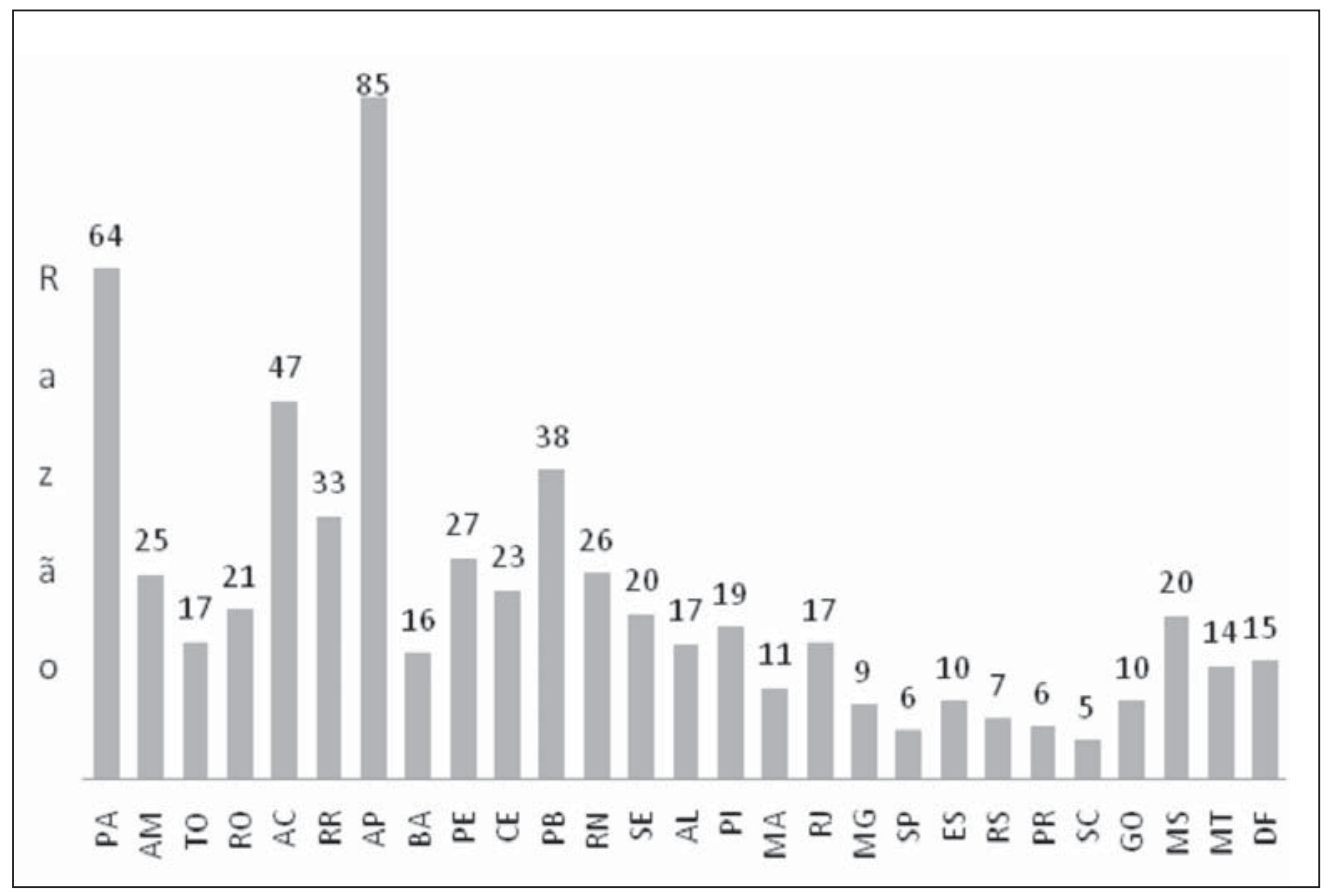

Fonte: Elaboração própria, baseado em Geocapes, 2014

Gráfico 3. Razão de doutores versus patentes no Brasil por estado. Ano: 2012

Muito embora sabendo que não se podem estabelecer relações de causalidade, constata-se que a Região Norte apresenta a pior relação doutores versus patentes: no estado do Amapá, existem 85 doutores para cada pedido de patente; no estado do Pará, 64 doutores para um pedido de patente; e, no estado do Acre, 47 doutores para cada pedido de patente. Pode-se observar que o estado de Santa Catarina obteve a melhor relação doutores versus patentes: são apenas cinco doutores para cada pedido de patente, seguido dos estados do Paraná e de São Paulo, com seis doutores para cada pedido de patente. No período analisado, as regiões Sul e Sudeste mantêm-se na melhor relação doutores versus patentes, e a razão mais desfavorável, em termos de inovação, está na Amazônia, ou seja, nessa região, a maioria dos doutores não contribuem para a concretização de processos inovativos. Mesmo sabendo que as regiões Sudeste e Sul são as mais industrializadas, que algumas patentes são registradas pelo setor produtivo e, ainda, que esse processo está em fase de mudança (CGEE, 2010), os dados ratificam que a maioria dos doutores na Amazônia tem suas atividades voltadas para outras atividades que não as inovativas, que, comprovadamente, 
poderiam contribuir para o crescimento econômico. No entanto, talvez a região se encontre em um estágio anterior e, por isso, ainda necessita formar capacidade local. Analisaremos a seguir a relação do número de doutores com a riqueza.

Ao estabelecer uma relação entre o número de doutores e o PIB per capita por região em relação ao Brasil, pretendíamos perceber se o conhecimento existente na região era proporcional à riqueza gerada. Esperávamos que, quanto maior a proporção regional do PIB per capita, maior fosse a proporção de doutores dessa mesma região, investigando se, como na literatura, haveria alguma causalidade.

No entanto, o Gráfico 4 revela mais uma vez as disparidades regionais: o Norte participa com 13\% do PIB per capita nacional, porém possui apenas $5 \%$ dos doutores do País. Mas não se pode deixar de registrar que a região mais heterogênea é o Centro-Oeste, que detinha 26\% do PIB per capita e 7\% dos doutores do País, bem como a situação favorável da Região Sudeste, que possuía quase o mesmo percentual do PIB per capita do Centro-Oeste, 27\%, e, no entanto, detinha o maior número de doutores do Brasil: 52\% do total. De acrescentar que essa maior concentração de doutores permite usufruir ainda dos efeitos de aglomeração e de transbordamento para o setor produtivo (NELSON, 2006). Entre as regiões, o Sul estava mais equilibrado, com $24 \%$ do PIB per capita e $18 \%$ do total de doutores; e o Nordeste, com $10 \%$ do PIB per capita e $18 \%$ dos doutores. 


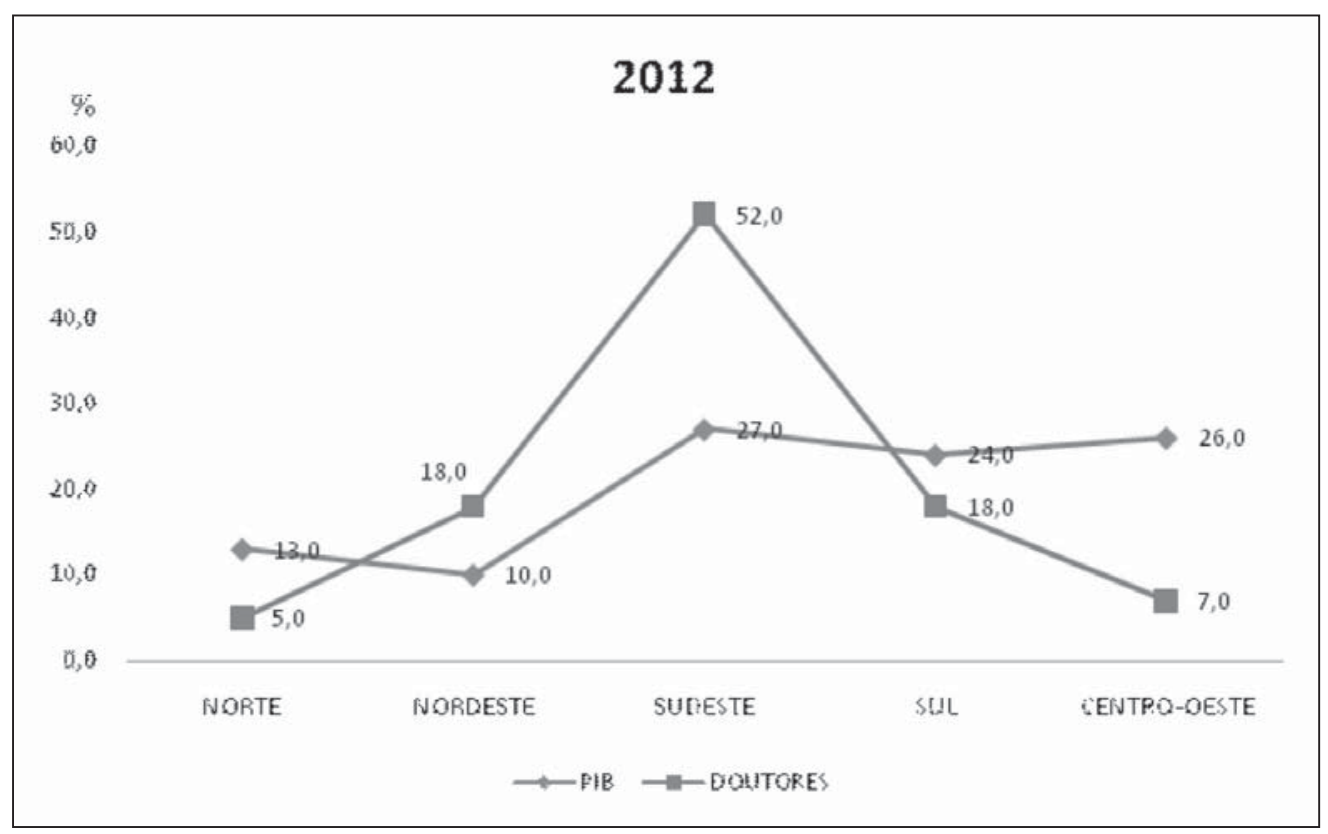

Fonte: Elaboração própria, baseado em Geocapes e IBGE, 2014.

\section{Gráfico 4. Proporção de doutores versus PIB per capita por região, 2012}

Os dados revelaram que as regiões se comportam de forma diferente. O Sul e o Sudeste corroboram estudos anteriores: quanto maior a participação no PIB, maior o percentual de doutores; o Centro-Oeste e o Norte apresentam uma maior participação no PIB do que na proporção de doutores, o que, juntamente com o conhecimento que temos de sua base produtiva ser essencialmente baseada em commodities, nos leva a questionar o modelo de desenvolvimento dessas regiões.

A última variável analisada foi o IFDM. Confere-se no Quadro 3 que o IFDM mais elevado, no ano de 2010, foi o do estado de São Paulo: 0,8940 (considerado alto), acima do IFDM do Brasil, que foi de 0,7899. Pode-se verificar também nesse gráfico a desigualdade nas regiões do Brasil, ficando com o Norte e o Nordeste os índices mais baixos; entre os estados destaca-se Alagoas, que apresenta o pior índice, com um IFDM de 0,5943. 
Quadro 3. IFDM por estado, 2000 e 2010

\begin{tabular}{|c|c|c|}
\hline UF & 2000 & 2010 \\
\hline PA & 0,51 & 0,63 \\
\hline AM & 0,48 & 0,62 \\
\hline TO & 0,50 & 0,69 \\
\hline $\mathrm{RO}$ & 0,56 & 0,72 \\
\hline$A C$ & 0,50 & 0,63 \\
\hline $\mathrm{RR}$ & 0,55 & 0,65 \\
\hline$A P$ & 0,53 & 0,62 \\
\hline BA & 0,51 & 0,68 \\
\hline PE & 0,56 & 0,73 \\
\hline CE & 0,54 & 0,73 \\
\hline PB & 0,51 & 0,66 \\
\hline RN & 0,54 & 0,69 \\
\hline SE & 0,53 & 0,69 \\
\hline$A L$ & 0,48 & 0,59 \\
\hline $\mathrm{PI}$ & 0,49 & 0,66 \\
\hline MA & 0,49 & 0,63 \\
\hline RJ & 0,66 & 0,82 \\
\hline MG & 0,63 & 0,82 \\
\hline $\mathrm{SP}$ & 0,73 & 0,89 \\
\hline ES & 0,62 & 0,78 \\
\hline $\mathrm{RS}$ & 0,65 & 0,82 \\
\hline PR & 0,65 & 0,84 \\
\hline SC & 0,64 & 0,83 \\
\hline GO & 0,59 & 0,76 \\
\hline MS & 0,61 & 0,73 \\
\hline MT & 0,56 & 0,73 \\
\hline $\mathrm{DF}$ & 0,67 & 0,77 \\
\hline
\end{tabular}

Fonte: Elaboração das autoras, Firjan 2014.

Quando se analisa a evolução do crescimento por estados ou por regiões (Gráfico 5), nota-se que foi no estado do Ceará, no Nordeste, onde o índice mais cresceu nos últimos anos, 20\%, no período pesquisado entre 2000 e 2010, indicando melhorias mais significativas nos indicadores sociais - emprego e renda, educação e saúde. Observa- 
se um crescimento equivalente entre as regiões, com destaque para o Sul, com um crescimento entre seus municípios de 18\% (o maior), e para o Norte, com um crescimento de 13\% (o menor).

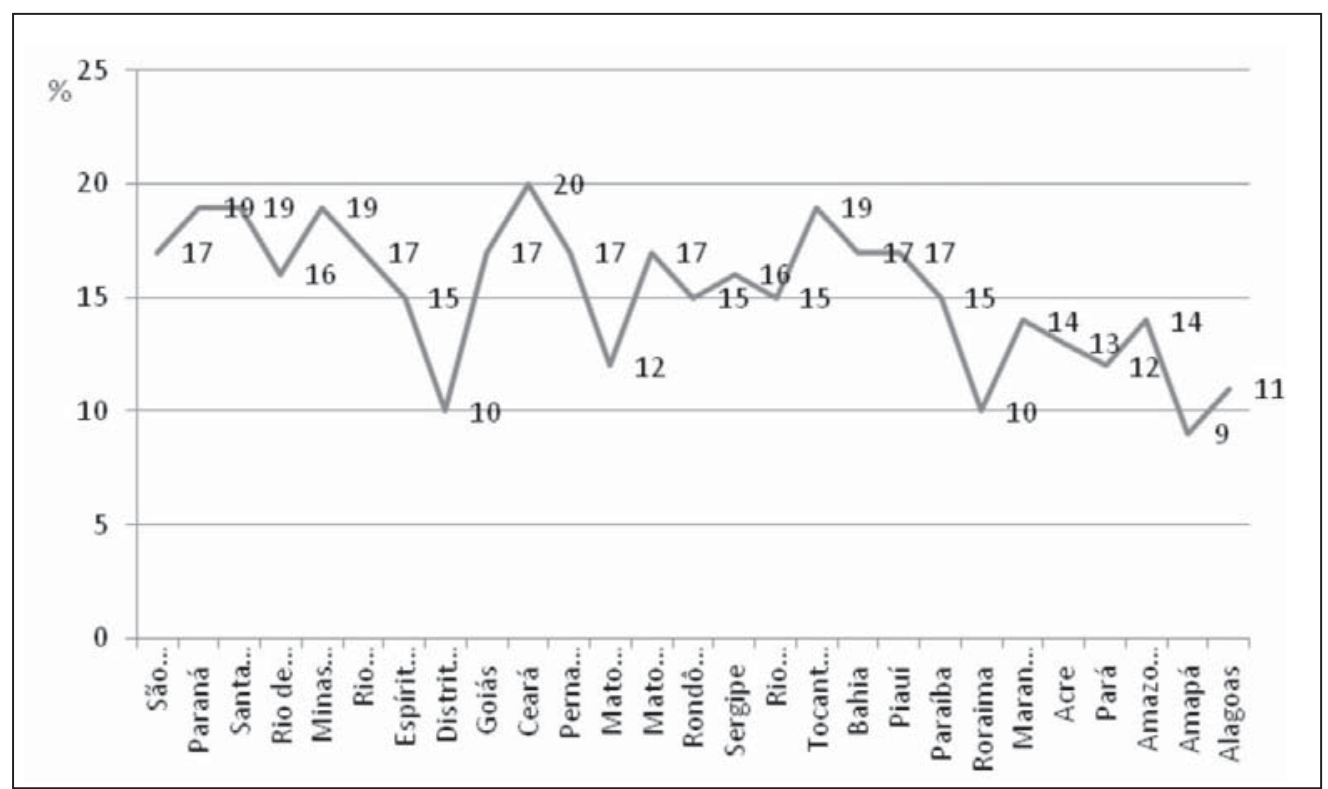

Fonte: Adaptado pelas autoras, baseado no Sistema Firjan, 2014.

\section{Gráfico 5. Evolução do IFDM}

Esse indicador, juntamente com os outros analisados nesta seção, mostra que, apesar de ainda haver desigualdade regional, de renda e de distribuição dos cursos de pós-graduação no País, o cenário vem mudando. Já se podem notar pequenas mudanças no crescimento das regiões em relação ao Sudeste, que sempre teve os melhores índices - os dados demostram menor crescimento dessa região no período estudado, configurando movimento de convergência das regiões mais periféricas. Esse panorama, segundo a literatura, acompanha a desconcentração geográfica do processo produtivo que vem ocorrendo no Brasil nos últimos anos. Estudos demonstram que várias indústrias se estenderam para regiões menos desenvolvidas (CAMPOLINA DINIZ, 1994; CANO, 1985), exigindo da população local conhecimento, o que eleva a demanda por educação, aumentando a oferta de emprego, promovendo maior geração de renda e proporcionando melhoria na qualidade de vida da sociedade. 


\section{Análise de medidas de associação, especialização e reestruturação}

Além da análise descritiva dos dados, procurou-se estabelecer análises que permitissem medir graus de relação entre as variáveis. Iniciou-se com o coeficiente de correlação com todas as variáveis já descritas na coleta de dados, em todos os estados, referentes ao período entre 2000 a 2012. Observa-se que o PIB per capita utilizado foi o de 2010, pois somente até o referido ano os dados se encontram disponiveis em meio eletrônico para consulta. Em uma análise geral, concluiu-se que essa falta de dados não prejudicaria os estudos, e se analisou a correlação com as variáveis que medem o desenvolvimento.

Quadro 3. Correlação entre as variáveis, período entre 2000 e 2012

\begin{tabular}{l|l|l}
\hline Variáveis & $\mathbf{2 0 0 0}$ & $\mathbf{2 0 1 2}$ \\
\hline Doutores X Patentes & 0,951 & 0,982 \\
\hline PIB X Ciência básica & 0,330 & 0,449 \\
\hline PIB X Interdisciplinar & 0,441 & 0,510 \\
\hline PIB X Doutores & 0,385 & 0,511 \\
\hline PIB X Patentes & 0,366 & 0,497 \\
\hline IFDM X Patentes & 0,675 & 0,661 \\
\hline IFDM X Doutores & 0,711 & 0,650 \\
\hline IFDM X Ciência básica & 0,660 & 0,559 \\
\hline IFDM X Interdisciplinar & 0,672 & 0,650 \\
\hline
\end{tabular}

Fonte: Elaboração própria, baseado em IBGE/Capes/Firjan/Inpi, 2014

Podemos ler no Quadro 3 que o coeficiente de correlação mais elevado, ou seja, que está mais próximo de 1, corresponde àquele entre o número de doutores e o número de patentes, nos anos de 2000 a 2012, sucessivamente $(0,951$-0,982), corroborando a literatura de inovação.

O coeficiente de correlação entre o PIB per capita e as outras variáveis foi de baixo a moderado, indicando pouca relação entre o aumento da riqueza no País e a inovação.

O índice de correlação entre o IFDM e todas as outras variáveis medindo inovação foi positivo e moderado, indicando que no Brasil existe relação entre um indicador mais abrangente de desenvolvimento 
econômico e os de inovação. Pelas análises anteriores, percebemos que essa relação, quando analisada por região/estado, apresenta diferenças entre o Sudeste e o Norte.

De destacar que, enquanto a relação linear entre PIB per capita e inovação, mesmo baixa, melhora na década, a de IFDM (que leva em consideração, além de renda, saúde e educação) com os indicadores de inovação, apesar de mais elevada, piora, indicando que os ganhos de renda que a população apresenta na última década começam a ter alguma relação com a inovação. No entanto, quando medimos o desenvolvimento socioeconômico dos indivíduos por meio de um indicador mais abrangente, o grau de relação diminui na década, indicando que, talvez, os componentes educação e saúde estejam sendo negligenciados.

Por fim, pesquisamos a composição da formação em pósgraduação para as regiões. Monteiro (2010) argumenta que o índice de especialização na Amazônia é muito mais voltado para os cursos multidisciplinares do que para os cursos da área de Engenharia, contrastando com as demais regiões, principalmente o Sudeste, onde o perfil de especialização é mais voltado para os cursos finalísticos. Esse perfil de instituições generalistas, segundo o autor, ocorre principalmente em regiões periféricas, e esse tipo de especialização contribui menos para o desenvolvimento regional.

Para o cálculo dos coeficientes de especialização e restruturação, utilizaram-se os dados coletados referentes aos programas de pósgraduação por grande área no Brasil no período de 1999 e 2012.

Tabela 1. Coeficientes de especialização e restruturação por regiões em relação ao nacional, período de 1999 a 2012

\begin{tabular}{|c|c|c|c|c|c|c|}
\hline & \multicolumn{2}{|c|}{$\begin{array}{l}\text { Coeficiente de } \\
\text { Especialização }\end{array}$} & \multicolumn{2}{|c|}{$\begin{array}{l}\text { Coeficiente de } \\
\text { Especialização }\end{array}$} & \multicolumn{2}{|c|}{$\begin{array}{c}\text { Coeficiente de } \\
\text { Reestruturação }\end{array}$} \\
\hline & 2012 & $\%$ & 1999 & $\%$ & 1999-2012 & $\%$ \\
\hline Norte & 14,999 & 0,15 & 27,921 & 0,28 & 27,38 & 0,27 \\
\hline Nordeste & 6,849 & 0,07 & 8,062 & 0,08 & 4,08 & 0,04 \\
\hline Centro-Oeste & 8,491 & 0,08 & 15,990 & 0,16 & 6,57 & 0,07 \\
\hline Sudeste & 5,940 & 0,06 & 7,618 & 0,08 & 5,03 & 0,05 \\
\hline Sul & 3,713 & 0,04 & 7,913 & 0,08 & 1,93 & 0,02 \\
\hline
\end{tabular}

Fonte: Elaboração própria, a partir de dados Geocapes, 2012, segundo Haddad (1989). 
Pode-se verificar na tabela acima que os coeficientes de especialização não são muito elevados e se aproximam de zero. 0 maior coeficiente entre as regiões, ou seja, a mais especialista nos dois anos é a Norte (0,28 em 1999 e 0,15 em 2012), que tem um nível 2,5 vezes superior à região Sudeste, seguida do Centro-Oeste. Em todas as regiões houve decréscimo nos coeficientes de especialização entre 1999 a 2012; no entanto, destacam-se as regiões Norte e Centro-Oeste, que diminuem sua especialização à metade, indicando que as regiões se aproximam mais rapidamente que as outras de um padrão nacional.

No período considerado, os coeficientes acima revelam que a Região Sul é aquela que se tem mantido mais semelhante, pois o resultado do coeficiente de reestruturação é mais próximo de zero. A Região Norte mantém no período um maior nivel de especialização, que é dez vezes superior ao da Região Sul - apesar de serem baixos, os valores nos permitem concluir que estamos longe de uma mudança estrutural na formação em pós-graduação em relação ao padrão nacional, indicando que a região é periférica em relação ao centro.

\section{Considerações finais}

Neste artigo foram analisadas algumas relações entre a pós-graduação e o desenvolvimento regional no Brasil, com base no referencial teórico que discute o desenvolvimento de países por meio do investimento em educação, principalmente na pesquisa básica (NELSON, 2006; STOKES, 2005; MOWERY; ROSENBERG, 2005), e acreditando no avanço tecnológico como fator fundamental para o desenvolvimento econômico. A condição de periferia de um país ou região se caracteriza por um menor grau de investimentos em relação ao centro. Apesar dos avanços aqui demonstrados, o Brasil continua investindo menos em C\&T que seus pares emergentes e os países com que pretende fazer catch-up. Deve-se acrescentar que o Brasil, por suas dimensões continentais e pela dificuldade em implementar, fora do centro (Sudeste), os diversos planos de organização territorial como um todo, apresenta uma dificuldade a mais devido às desigualdades regionais internas. 
Historicamente, assistiu-se a uma incapacidade de diálogo entre as instituições de base local com o governo central, e as relações de comércio e de investimento foram definindo a centralidade brasileira. A região brasileira mais periférica continua sendo o Norte, que inclui a Amazônia, com características climáticas e populacionais peculiares (esparsa população rural e alta densidade domiciliar urbana) e indicadores de desenvolvimento socioeconômico muito baixos, baixa produtividade per capita, baixa capacidade de formação e, consequentemente, de absorção de conhecimento e produção do novo. Para mudar o quadro existente, Homma (2008) escreve que na Amazônia faltam todos os tipos de pesquisa: a pura, a aplicada e a baseada no uso.

Assim, este estudo analisou um dos fatores que podem redefinir o processo de desenvolvimento e, dessa forma, diminuir a distância entre o centro e as regiões periféricas (ou ultraperiféricas, se levarmos em consideração que o Brasil é uma nação periférica): a formação de quadros responsáveis pela pesquisa e, idealmente, inovação. De modo geral, foi observado que os programas de pós-graduação, tanto das ciências básicas quanto da área interdisciplinar, tiveram um crescimento bastante significativo, ressaltando que, em termos proporcionais, os cursos interdisciplinares foram os que mais se expandiram; atrelado ao crescimento dos programas de pós-graduação, aumentou o número de doutores, com destaque para as regiões mais periféricas, o Norte e o Centro-Oeste, e o Nordeste, onde o número de doutores mais cresceu, demonstrando a existência de universidades mais dinâmicas.

No que tange à relação entre o crescimento do número de doutores e o depósito de patentes, utilizado em alguns trabalhos como indicador de inovação tecnológica, constatou-se que o conhecimento mais avançado, adquirido por meio da formação de doutores, não está sendo utilizado para fins de inovação. Esse indicador demonstrou claramente as diferenças regionais e estaduais; os estados da Região Norte depositam poucos pedidos de patentes e apresentam um ratio baixíssimo de número de patentes por doutor. Macapá “necessita” de 85 doutores por pedido de patente, enquanto Santa Catarina, o estado com maior produtividade, a cada cinco doutores faz um pedido de patente. 
Naturalmente, devemos levar em conta que as patentes não são todas pedidas por doutores e que, na maioria das vezes, os pedidos são do setor produtivo, ainda que no Brasil esse valor seja bem menor do que em outros países emergentes, como China, Coreia do Sul ou Tailândia (INPI, 2013). A Região Norte é aquela que apresenta o menor grau de industrialização e, ao mesmo tempo, aquela que, estando em um estágio menos avançado na formação de novos quadros, necessita que seus doutores se dediquem mais à docência. No entanto, para ultrapassar a condição periférica, a velocidade de avanço tem que ser maior, e, nesse caso, a Região Nordeste está tendo melhor desempenho nos indicadores estudados.

No sentido de explorar um pouco mais o papel desses avanços no desenvolvimento do País, analisaram-se as correlações do PIB per capita e IFDM, indicadores comumente usados para medir crescimento econômico, com as demais variáveis. Quando a correlação é entre o PIB per capita e as demais variáveis (patentes, doutores, ciência básica, interdisciplinar e graduação), verificou-se que os índices encontrados foram menores do que quando a análise foi feita entre o IFDM e as demais variáveis, o que pode ser considerado um ponto positivo para o País, visto que o IFDM é um indicador socioeconômico mais completo, pois mede saúde, educação e renda. No entanto, constatou-se queda na década, o que induz à necessidade de se fazerem novas pesquisas com outros indicadores ou séries históricas mais longas para se perceber se está havendo ou não um processo de convergência.

Foram analisados os dados referentes à formação da pós-graduação, seguindo discussões recentes que apontam a interdisciplinaridade como uma necessidade da sociedade do conhecimento, globalizada e em rede, como impõe a ciência moderna.

Observou-se que, apesar do crescimento da pós-graduação como um todo no País e proporcionalmente em maior medida na Região Norte, são criados mais cursos generalistas do que cursos finalísticos. Devese ressaltar que só muito recentemente a região apresenta capacidade de criar cursos de pós-graduação disciplinares, pois não tinha quadros 
suficientes para apresentar propostas viáveis de abertura de novos cursos. Os resultados dos coeficientes de especialização indicaram que a Região Norte é a que mais avançou no sentido de se tornar menos especialista (característica periférica) em relação ao resto do País. No entanto, o coeficiente de reestruturação, que mede a mudança estrutural no período considerado (1999-2012), demonstra que é a região que menos muda e que se faz um pouco mais do mesmo. Sinal de baixa capacidade de inovar na concepção mais mainstream por intermédio das ciências básicas ou em relação à área do conhecimento interdiscipinar, fator essencial para os desafios da sociedade atual (CASTELLS, 2002; PHILLIPI JR; NETO, 2011)?

A literatura abordada discute, por um lado, a ideia de que o conhecimento em ciência básica é essencial para o desenvolvimento tecnológico e eleva as possibilidades de crescimento econômico, somando pesquisa, inovação e desenvolvimento como elementos essenciais para o desenvolvimento regional. E, por outro lado, que a interdisciplinaridade é uma necessidade do conhecimento globalizado imposto à ciência moderna, indicando, segundo os autores, um conhecimento mais elevado. Não há dados que comprovem que tais ciências possam contribuir ou tenham contribuído para o desenvolvimento de determinada região; também não é o objetivo deste trabalho demonstrar qual das ciências é a mais importante, mas, sim, analisar as duas correntes. Sugere-se, portanto, que se façam análises posteriores nesse sentido.

Quanto à oposição generalista versus finalística, apesar dos resultados da correlação serem ligeiramente superiores para a interdisciplinar em relação às ciências básicas, os resultados não são conclusivos e não se acredita que se deva optar por um em detrimento do outro, dado o pouco acesso à formação superior no País.

Deve-se acrescentar que o Brasil ainda busca satisfazer suas necessidades básicas, como erradicar a pobreza, melhorar a distribuição de renda, aumentar o acesso ao saneamento, educação etc. Seus índices de desenvolvimento humano e social ainda estão muito baixos se comparado com os de outros países. Acrescente-se que a 
inovação tecnológica, ponto-chave para o desenvolvimento econômico, necessita de maior articulação institucional. As universidades mantêm um papel importante nesse contexto: o de qualificar pessoas que vão gerar e absorver o conhecimento necessário para a inovação e, consequentemente, contribuir para o desenvolvimento das regiões onde estão inseridas.

O estudo apontou algumas conexões para o desenvolvimento regional virtuoso: um investimento em educação maior e mais focado nas regiões periféricas; uma interação melhor entre a universidade e a sociedade, principalmente entre a produção local e a pesquisa acadêmica; a criação de novos cursos de graduação e de pós-graduação voltados para atender as atividades econômicas das regiões; incentivo aos doutores e aos alunos para se dedicarem à pesquisa tecnológica; e a criação de mais instituições públicas voltadas para a disseminação do conhecimento, como as universidades e os institutos tecnológicos, principalmente nas regiões periféricas.

Partindo dos resultados aqui apresentados em relação ao esforço de formação empreendido no País, será interessante explorar mais experiências e vocações de cada região. Estudos de aprendizagem, desde os mais clássicos (e.g., PIAGET, 1952; VYGOTSKY, 1978 apud LATTUCA; VOIGHT; FATH, 2004) aos mais recentes (NEWELL, 1994; ROGOFF, 2003 apud LATTUCA; VOIGHT; FATH, 2004), dedicados ao estudo de aprendizagem interdisciplinar, demonstram que a aprendizagem de conteúdos interdisciplinares e mais conectados com o contexto de cada estudante tem mais chances de absorção e desenvolvimento. Na linha de Phillipi Jr. e Silva Neto (2011) se entende que, para lidar com a complexidade da sociedade brasileira, é necessária a formação interdisciplinar. No entanto, é necessário perceber que na periferia as experiências vividas são limitadas e que a formação de base não apresenta a mesma solidez que no centro. Assim, a interdisciplinaridade, por ser mais próxima cognitivamente, permite melhor absorção de conhecimentos, de motivação e de estabelecimento dos links necessários à sociedade em rede por parte dos formandos, desde que baseada em um lock-in de informação e de conhecimento que expande 
a distância ao centro em vez de se verificar a convergência. A expansão da pós-graduação é um fator importante, mas corre-se o risco de que não encontre eco na formação e supostamente no desenvolvimento que se pretende. Nas regiões mais periféricas, para se notarem seus efeitos, seriam necessárias políticas públicas focais e várias frentes de investimento em todos os níveis da educação, concomitantemente, para se produzir uma efetiva e mais equitativa mudança social.

\section{Referências bibliográficas:}

ALBUQUERQUE, E. da M. Inadequacy of technology and innovation systems at the periphery: notes on Celso Furtado's contributions for a dialogue between evolutionists and structuralists. Textos para Discussão. Belo Horizonte: UFMG: Cedeplar, 2005.

AlBuquerque, E. da M.; SILVA, L. A. ; PÓVOA, L. Diferenciação intersetorial na interação entre empresas e universidade no Brasil. São Paulo em Perspectiva, v.19, n.1, p. 95-104, jan./mar. 2005. Disponivel em: <www.scielo.br/pdf/ssp/v19n1/v19n1a08.pdf>. Acesso em: 01 maio 2011.

ARBIX, G.; ZILBOVICIUS, M.; ABRAMOVAY, R. (Org.). Razões e ficções do desenvolvimento. São Paulo: Unesp; Edusp, 2001.

BARBETTA, P. A. Estatísticas aplicadas às Ciências Sociais. Florianópolis: UFSC, 2005.

CAMPOLINA DINIZ,C. A Dinâmica regional recente da economia brasileira e suas perspectivas. Brasília: Ipea, 1994.

CANO, W. Desequilíbrios regionais e concentração industrial no Brasil: 1830-1970. São Paulo: Global: Unicamp, 1985.

CAPES - Coordenação de Aperfeiçoamento de Pessoal de Nível Superior. Documento de avaliação continuada: área interdisciplinar. 
2009. Disponível em: <http://qualis.capes.gov.br/arquivos /avaliacao /webqualis/criterios2007_2009/Criterios_Qualis_2008_45.pdf>. Acesso em: 03 jun. 2011.

GeoCapes. 2011. Disponível em: <http://geocapes.capes.gov. br/geocapesds/\#>. Acesso em: abr. 2011 e abr. 2014.

CARDOSO, F. H. Development under Fire. Mexico D.F.: Instituto Latinoamericano de Estudios Transnacionales, 1979.

CASSIOLATO, J. (Coord.). Perspectivas do investimento na economia do conhecimento. Campinas: Unicamp: Instituto de Economia, 2010. (Projeto PIB - Perspectiva de investimento no Brasil, v. 3).

CASTELLS, M. A sociedade em Rede. Tradução de Alexandra Lemos e Tânia Soares. Lisboa: Fundação Calouste Gulbenkian, 2002. 713 p.

CGEE - Centro de Gestão e Estudos Estratégicos. Doutores 2010: estudos da demografia da base técnico-científica brasileira. Brasília, 2010. Disponivel em: <http:/ /www.cgee.org.br>. Acesso em: mar. 2011 e abr.2014.

COHEN, W.; LEVINTHAL, D. Inovation and learning: the two faces of R\&D. The Economic Journal, v. 99, n. 397, p. 569-596, 1989.

COSTA, L. C. B. F. Novos rumos e perspectivas. Brasília, DF: Brasiliana, 2005

FIRJAN - Federação das Indústrias do Estado do Rio de Janeiro. Índice Firjan de Desenvolvimento Municipal. Rio de Janeiro, 2010. Disponível em: <http:/ /www.firjan.org.br/ifdm/>. Acesso em: abr 2014.

GOODMAN, P. S. Technology and Organization. São Francisco: Josseybass, 1989.

HADDAD, P. R. (Org.). Economia regional: teorias e métodos de análise. Fortaleza, CE: Etene, 1989. 694 p. 
HOMMA, A. K O. Extrativismo, biodiversidade e biopirataria na Amazônia. Textos para Discussão, n. 27. Brasília, DF: Embrapa Informação Tecnológica, 2008.

IBGE - Instituto Brasileiro de Geografia e Estatística. Séries Históricas e Estatísticas. 2011. Disponível em: <www.ibge.gov.br>. Acesso em: abr. 2011 e abr. 2014.

INEP - Instituto Nacional de Estudos e Pesquisas Educacionais Anísio Teixeira. DEED. 2010. Disponivel em: <http://portal.inep.gov.br/web/ censo-da-educação-superior>. Acesso em : 19 abr. 2011.

INPI - Instituto Nacional de Propriedade Industrial. Estatísticas Anuais 2000 - 2012. Patentes. 2013. Disponível em: <www.inpi.gov.br>. Acesso em: 10 abr. 2014.

LATTUCA, L. R.; VOIGHT, L. J.; FATH, Q. F. Does Interdisciplinarity Promote Learning? Theoretical Support and Researchable Questions. The Review of Higher Education, v. 28, n. 1, p. 23-48, 2004.

LÜNDVALL, B. A. The Social Dimension of the Learning Economy. DRUID Working Paper, Aalborg, n. 23, 1996.

MADEIRA, M. C. de. Estudos Interdisciplinares de Representação Social. Goiânia, GO: Alternativa, 2000.

McCANN, P. Globalization and economic geography: the world is curved, not flat. Cambridge Journal of Regions Economy and Society, v.1, n.3, p.351-370, 2008.

MONTEIRO, M. A institucionalidade da ciência, tecnologia e inovação na Amazônia e a conformação de trajetórias e paradigmas tecnológicos. Novos Cadernos NAEA, Belém, PA, v. 13, n. 2, p. 235-260, dez. 2010.

MOWERY, D. C.; ROSENBERG, N. Trajetórias da inovação: a mudança tecnológica nos Estados Unidos da América no século XX. Tradutor Marcelo Knobel. Campinas, SP: Unicamp, 2005. 
NELSON, R. As fontes do crescimento econômico. Tradutora Adriana Gomes de Freitas. Campinas, SP: Unicamp, 2006.

NORTH, D. C.; THOMAS, R.P. The Rise of the Western Word: a new economic History. Cambridge: Cambridge University Press, 1973.

PHILIPPI JÚNIOR, A.; SILVA NETO, A. (Ed.). Interdisciplinaridade em ciência, tecnologia \& inovação. Barueri, SP: Manole, 2011.

ROMEIRO, C. J. Impacto econômico das universidades paranaenses. Curitiba, PR: Artmed, 1998.

SBPC - Sociedade Brasileira para o Progresso da Ciência. Jornal da Ciência; 2010. Disponível em : <http://www.jornaldaciencia.org.br/ Detalhe.php?id=69003>. Acesso em: maio 2014.

SCHILLER, D.; MILDAHN, B.; REVILLA DIEZ, J. Barriers against the transfer of knowledge between universities and industry in newly-industrialised countries: an analysis of university-industry linkages in Thailand. In: VARGA, A. (Org.). Universities, Knowledge Transfer and Regional Development. Elgar: Cheltenham, 2009.

SERRA, M.; ROLIM, C. Instituições de Ensino Superior e Desenvolvimento Regional: O caso da Região Norte do Paraná. Revista de Economia, v.35, n.3 (ano 33), p. 87-102, set/dez. 2009. Editora UFPR. Disponível em: <http://ojs.c3sl. ufpr.br/ojs2/index.php/economia/article/ view/16710>. Acesso em: 10 jul. 2011.

STOKES, D. E. O quadrante de Pasteur - a ciência básica e a inovação tecnológica. Tradutor José Emílio Maiorino. Campinas: Unicamp, 2005.

SUZIGAN, W.; ALBUQUERQUE, E. da M. e. A interação entre universidades e empresas em perspectiva histórica no Brasil. Belo Horizonte: UFMG: Cedeplar, 2008.

TOYOSHIMA, S. H. Instituições e desenvolvimento econômico - uma análise crítica das idéias de Douglass North. In: ENCONTRO NACIONAL DE ECONOMiA POLíTICA, 3., 1999, Niterói. Anais... Niterói: Eduff, 1999. 
VÁZQUEZ-BARQUERO, A. Desarrollo, redes e innovación: lecciones sobre desarrollo endógeno. Madri: Ediciones Pirámide, 1998.

WALLERSTEIN, I. World-systems Analysis. In: MODELSKI, G. (Ed.). World System Hystory. Oxford, UK: Eolss Publishers, 2004. 